\title{
Far North Queensland
}

\section{Flick, Brigitta ${ }^{1}$, Nerina Caltabiano ${ }^{2}$, Joan Bentrupperbäumer ${ }^{3}$}

Department of Psychology, James Cook University, PO Box 6811, Cairns QLD 4879, Australia, brigitta.flick@ jcu.edu.au, ${ }^{1}$ Department of Psychology, James Cook University, nerina.caltabiano@jcu.edu.au, ${ }^{2}$ School of Earth and Environmental Sciences, James Cook University, joan.bentrupperbaumer@jcu.edu. $\mathrm{au}^{3}$

\begin{abstract}
Landowners (100 males and 21 females) within the catchment of the Great Barrier Reef Lagoon located between the Barron and the South Johnstone Rivers responded to a postal survey assessing attitudes towards their streamside forests. 121 useable questionnaires were used to identify the underlying components within landowner's attitudes. Factor analysis revealed two components, namely, awareness of human impact on local streamside forest, and appreciation of environmental benefits and functions of streamside forest. Only factor 2, appreciation of environment benefits and functions of streamside forest, was found to significantly predict good streamside forest management practices as self-reported by landowners. There is a need to understand the human impact on streamside zones.
\end{abstract}

Far North Queensland is an area of global biological significance. It contains two World Heritage areas that were listed based on natural attributes alone and fulfilled all four World Heritage criteria. The Great Barrier Reef (GBR) was declared World Heritage in 1981 and the Wet Tropics in 1988 (World Heritage List, 2009). The lowlands of the GBR Catchment in the study area are comprised almost entirely of private land that is largely farmed and urbanised. In the course of time since European settlement much of the native vegetation was cleared, especially the streamside forests were diminished or destroyed (Productivity Commission, 2003). These land modifications together with European farming methods have a significant impact on water quality in the creeks and rivers that flow into the Great Barrier Reef Lagoon (Brodie, 2002; Brodie \& Mitchell, 2005; Devlin \& Brodie, 2005; Gilbert, 2001; Queensland Government, 2008; Rasiah, et al., 2003; Werren \& Arthington, 2002).

Streamside vegetation is comprised of native trees, bushes and grasses, and is needed to stabilise the banks and stream beds. Their biophysical function is essential for good water quality. It is based on the forests' ability to filter out naturally occurring silt and sediments loads especially during floods, and to retain as well as remove agricultural and other 
chemicals from contaminated surface run-off (Bjornsson, et al., 2002; Klapproth\& Johnson, 1999a; Lovett \& Price, 2007; McKerkow, Prosser, Grayson, \& Heiner, 2004; Werren \& Arthington, 2002). Additionally they provide shade, shelter and food for native fauna and moderate the water temperature to allow the aquatic ecosystem to flourish (FNQ NRM Ltd \& Rainforest CRC, 2004; Herron \& Hairsine, 1998; Hobbs, Hussey, \& Saunders, 1990). Even debris in the waterways is beneficial in slowing down the flow of water during heavy rainfalls in the tropical wet summer (Webb \& Erskine, 2003).

High loads of nitrogen and phosphorous used in farming practices have been found in the river plumes (Devlin \& Brodie, 2005; Haynes, 2001; Rasiah et al., 2003; Werren, Hunt, \& Brodie, 2002) and are considered a great threat to the GBR. The reef is not able to tolerate large amounts of nutrients and silt, and polluted water in the catchment has become a major concern to the researchers and managers of the Great Barrier Reef Marine Park (Armour, Cogle, Rasiah, \& Russell, 2004; GBRMPA, 2001). Intact and functioning streamside forests are therefore necessary and have been found to be a key factor in the preservation of the GBR (Brodie, Lewis, Mitchell, Bainbridge,\& Waterhouse, 2009; Webb \& Erskine, 2003; Werren et al., 2002).

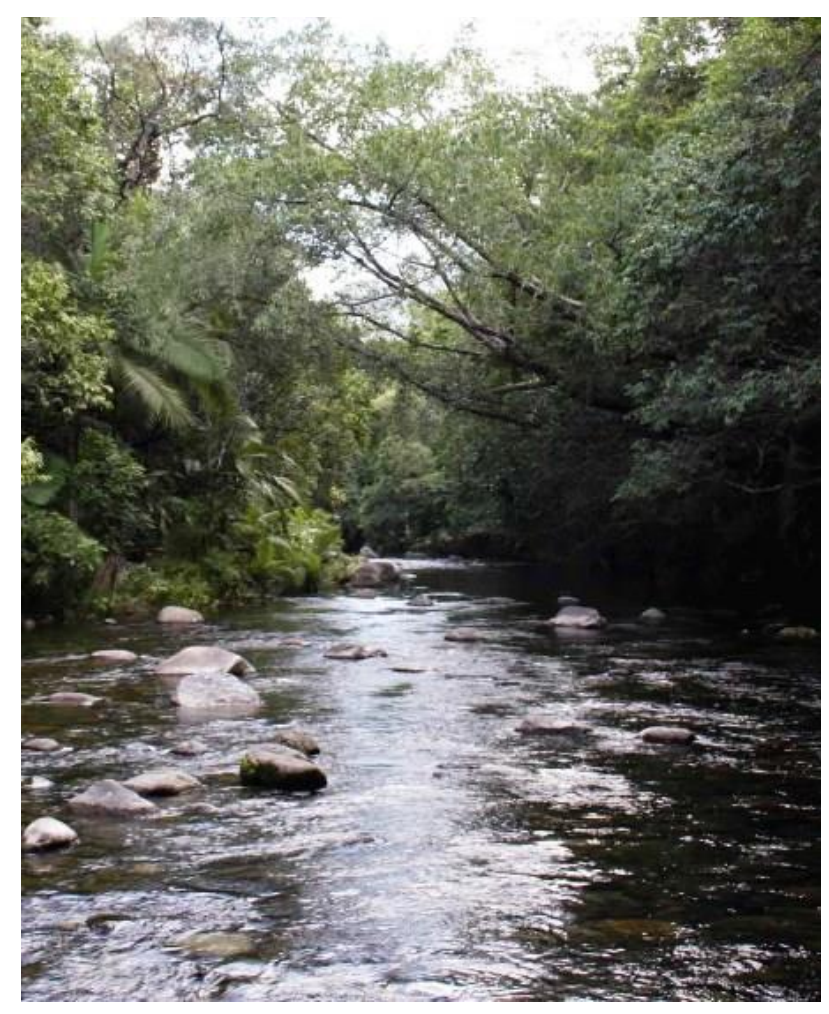

Figure 1. A creek in a well maintained streamside forest. 
The return of streamside forests to a state that has some semblance to that of pre-intensive agricultural times would not only benefit the environment but also enable Indigenous cultural activities (Wet Tropics Management Authority, 2004). Aborigines have used these waterways for millennia (Dixon, 1991), and such use of streamside forest resources needs to be protected for traditional fishing and gathering of plants, ensuring continuity of aboriginal culture. The preservation of native vegetation and clean water in the area would benefit the Great Barrier Reef, the waterways and all people who use them for recreation and traditional cultural practices.

Protecting the environment is dependent on a number of factors. In rare cases relatively small groups have the capability of bringing about significant changes due to ownership of significant resources. One of those cases is the group of landowners with streamside forests in the lowland water catchment of the Great Barrier Reef Lagoon in Far North Queensland. The health and survival of streamside forests is dependent on these landowners, and on their willingness to preserve and protect them. The benefits will not only be to the landowners but society at large because of the preservation of such significant ecological systems. For the landowners, monetary benefits flow from sustained maintenance of streamside areas such as decrease of soil loss, less need for herbicides, and less crop damage from vermin among others (Bjornsson et al., 2002; Mallawaarachchi, Ebert, Byron, \& Johnson, 1999; Werren et al., 2002; Wet Tropics Management Authority, 2004)

Despite extensive information on the significant beneficial functions of intact streamside forests, and recommendation of good management practices available to landowners from brochures, websites, land care groups, and workshops, the streamside forests are not in a healthy state (Cleary \& Amprimo, 1995; FNQ NRM Ltd\& Rainforest CRC, 2004; Productivity Commission, 2003; Thomson \& Pepperdine, 2003). In a report prepared for the Far North Queensland Natural Resource Management Agency, Fenton (2004) found that the amount of information available is not commensurate with the rate of adoption by landowners.

The assumption that landowners do not consider streamside forests special or valuable which results in neglecting or destroying them, is an interesting research question. In a report for the sugar industry in Far North Queensland it was expressed as "Clearly one of the most frequently offered impediments [to better management]... was associated with landholder attitudes" (Bjornsson et al., 2002, p. 24). Here the term "attitude" seems to refer to 
landowners' negative viewpoint or possibly a dislike of their streamside forest but does not tell us how this was ascertained or if it was based on particular beliefs. In social psychology "attitude" is a psychological construct that describes a person's degree of favour or disfavour toward an object or an action, and incorporates an understanding as well as a liking of the attitudinal object, or of performing a behaviour (Eagley \& Chaiken, 1993) such as practicing recommended land care management. As such attitudes are influenced by affective and cognitive stimuli about the object or action according to salient memories and thoughts, and sometimes deep seated beliefs.

Attitudes are only definable from people's responses to questions that have been specifically designed to target the attitudinal object. The strength of, for instance, affect for streamside forests, or appreciation of the beneficial nature of these areas can be measured on a scale, and the scores used to correlate the measure with the landowner's practices. Using this method of research a picture of likes and dislikes and the relative depth of the feelings and beliefs can be collated and used to assess their impact on landowners' practices in regard to streamside forest care.

Research with landowners has shown that attitude components such as appreciation and awareness of the functions of good land management practices positively influence farmers' streamside management (Curtis \& Robertson, 2003a; Curtis\& Robertson, 2003b; Curtis, Shindler, \& Wright, 2002; Dutcher, Finley, Luloff, \& Johnson, 2004; Kraack, 2000; Vanclay, 1992; Vogel, 1996). Disbelief in the biophysical functions of streamside forests, often combined with the failure to recognise the deteriorated state of their own streamside forests has been identified as one of the causes of water pollution and land degradation (Burston \& Mathison, 1997; Curtis\& Robertson, 2003a; Dutcher et al., 2004). This "blind spot" when it comes to one's own backyard, in part is either a failure to understand or believe information, or it has to do with the very large amount of information that often depicts extreme examples of streamside damage which don't seem applicable to the landowners (Kraack, 2000; Vanclay, 1992).

Identifying the attitudes underlying good streamside forest management practices can provide valuable information into understanding how to promote adoption of these practices (Klapproth \& Johnson, 1999b; Steg\& Vlek, 2008). It can of course also point to barriers that prevent adoption of environmentally positive practices (McKenzie-Mohr, 2000). 
The aim of the study is to identify underlying components within attitudes which distinguish landowners who care for their streamside forests from those who do not. The information about the state of the area is gathered from items on vegetation and land use of streamside forests as self-reported by respondents.

This paper is based on findings from a postal survey of landowners regarding their attitudes toward their streamside forests. The survey questionnaire incorporated a measurement of the components of attitudes using as the conceptual and analytical framework the social psychological model of the Theory of Planned Behaviour (TPB) (Ajzen, 1991). This model has been used extensively in environmental behaviour studies and found to have considerable predictive power (Armitage \& Conner, 2001; Fielding, Terry, Masser, Bordia, \& Hogg, 2005).

The focus of this paper is on the attitude component of the TPB model, leaving out the impact of perceived control and of social norming factors. The 34 attitude items were examined for major themes that are predictive of evidence of good streamside land care using factor analysis. Their relative contribution in the prediction of good streamside management was investigated using the statistical technique of multiple regression.

\section{METHOD}

\section{Study Design}

The survey was conducted as an anonymous postal survey. This design of keeping the responses completely anonymous was chosen to maximise the probability of eliciting genuine answers (Thorndike, 1997). It was felt that the subject matter might be something the respondents felt strongly about and their candid answers were needed. This design has not been shown to improve the return rate of surveys (Mangione, 1997). One reminder letter was sent to all valid addresses three weeks after the survey mail-out. Reminder letters have been found to always improve the return rate (Mangione, 1995).

\section{Participants}

\section{Selection and Composition}


The participants for the survey all had properties bounded by a waterway (creek, river, wetland, mangrove swamp) in the catchment of the Great Barrier Reef Lagoon located between the Barron and the South Johnstone Rivers (Cairns City Council and Johnstone Shire Council). The lot numbers were identified from the Geographic Information Service (GIS) data base and cadastral maps of the area and the corresponding property numbers were extracted from a digital data CD purchased from the Department of Mining and Industry.

The number of identified properties in the Cairns City and the Johnstone Shires amounted to 1174. The Cairns City and the Johnstone Shire Councils were then approached for the addresses of the owners of the properties. Both councils supplied the addresses free of charge. After removing the doubled-up addresses of multiple landowners, industrial complexes, and the Crown land properties from the list, the number of addresses was reduced to 569 (287 in the Cairns City Shire and 282 in the Johnstone Shire). Every address thus selected was included in the mail-out list. There was a further loss of 29 contacts that returned the unopened letter, leaving 540 valid respondents on the list.

Only 121 useable surveys were returned which represents a response rate of $22 \%$. Of this sample, 100 were males $(83 \%)$ and 21 were females (17\%). The majority of respondents were sugarcane farmers (55.4\%), other land uses included cattle farming (9.9\%), fruit and vegetable farming (14.9\%), and mainly residential (19.8\%).

\section{Materials and Procedure}

The survey consisted of a 19-page questionnaire with four sections (A, B, C, D), each beginning with a short explanatory note. The meaning of the term "waterways" was explained on the first page as including creeks, rivers, drains, and wetlands.

Twelve items were included inquiring about the conditions of the creeks, banks and their use as well as personal observations regarding vegetation changes over time. Five of these items focussed on the kinds of plants growing on the banks, the distance from the creek that the land is cultivated, and the type of vegetation left to grow or planted in the streamside zones. The responses to these were used as indicators of good streamside forest management practices and used in the analysis in this study. 
One section of the survey was structured to elicit responses according to the requirements of the social psychological Theory of Planned Behaviour (Ajzen, 1991). A 7-point Likert scale was used for the 34 attitude items of interest to this particular paper.

Ten direct attitude items were presented such as "I find streamside forests ...", 1 extremely pleasant to 7 extremely unpleasant; or "Maintaining of streamside forests is a waste of money and time", 1 strongly disagree to 7 strongly agree. The 24 indirect attitude items represented measures of the respondents' beliefs that expressed the respondent's evaluation of a proposed outcome, such as "To detoxify agricultural chemicals in the soil before they reach the waterways is ...", 1 extremely desirable to 7 extremely undesirable, or the respondent's belief in the strength of that outcome, "The roots of plants in streamside forests are capable of converting agricultural chemicals into non-toxic substances", 1 strongly agree to 7 strongly disagree.

The 19-page questionnaire was stapled to form a booklet. This, together with a letter of information, a consent form, and prepaid return envelopes were sent out in a large yellow envelope with a special edition postal stamp on it. The returned surveys contained no identification of the respondents and were completely anonymous. The survey mail-out took place in early October 2006.

\section{RESULTS}

\section{Data Analysis}

To minimise the number of attitude items and to investigate the underlying structure, the data of all 34 attitude items were subjected to a factor analysis. The principal components analysis followed by Varimax rotation separated two components consisting of 10 items each. These showed good internal consistency with Cronbach's Alpha coefficients of .86 and .88 respectively. The two components explained a total of $52 \%$ of the total variance (factor 1 accounted for $26.7 \%$ of the variance and factor 2 accounted for $25.3 \%$ ).

The attitude items within each factor were then examined for an overarching theme by four judges (colleagues in the Department of Psychology). The consensus was that factor 1 described: "Awareness of human impact on local streamside forests"; and factor 2: "Appreciation of environmental benefits and of functions of streamside zones". 
Factor 1-Awareness of human impact on local streamside forest:

1. Trees on the riverbanks are extremely good to have.

2. Only grass on the streamsides to stabilise them is insufficient.

3. Stabilising streamsides with bushes and trees works extremely well.

4. Shade in streamside forests benefits the creatures living in the creek

5. Grass alone extremely inefficient holding the creek banks together.

6. Streamside forest provides good habitat for creatures in the creek.

7. Growing bushes and trees works well in stabilising the stream banks.

8. Streamside forests mean more habitat for native animals.

9. Streamside forests are extremely pleasant.

10. Taking care of my streamside forests is of benefit to the environment.

Factor 2-Appreciation of environmental benefits and functions of streamside forest

1. Native animals in the streamside forest are very enjoyable.

2. Native animals in streamside forests are extremely good to have.

3. The preservation of my streamside forests is valuable.

4. Streamside forests are very good for the environment at large.

5. Maintaining of streamside forests is not a waste of money and time.

6. Reforesting my stream sides would be extremely desirable.

7. Streamside forests are very beneficial for the environment at large.

8. The environment benefits if landowners care for their streamside forest.

9. Streamside forests slow down flow of silt and sediments.

10. Intact streamside forests will assure good water quality in my creek.

To gain insight into how much the two attitude factors predict "good streamside forest management practices", multiple regression analysis was performed. The component "good streamside forest management practices" consisted of the sum of the yes-scores from five indicator items, providing a range of scores from 0 to 5.

Factor 1 Awareness of human impact on local streamside forest and factor 2 Appreciation of environmental benefits and functions of streamside forest explained $10 \%$ of the variance in streamside forest management practice, with a highly significant $(\mathrm{p}<0.001)$ contribution from factor 2 (factor 1 : Beta $=.14$; factor 2 : Beta $=.31$ ). 
The regression results indicate that attitudes that reflect appreciation of the function and environmental benefit of streamside forests are a significant predictor of landowners' streamside forest management practices in conjunction with an awareness of human impact on streamside forests.

\section{DISCUSSION}

The findings from the multiple regression analysis show that the two attitude factors do have an impact on good streamside forest management practices as self-reported by landowners. Landowners with high scores for well managed streamside forests were significantly more appreciative of the environmental benefits and the biophysical functions of streamside forests, although they did not demonstrate the same level of high awareness of the human impact on local streamside forest. The relatively low explained variance of $10 \%$ is considered a good and believable finding in social psychological models.

The landowners' awareness of their own impact on their streamside forest, as represented in factor 1, was expressed by the idea that beneficial streamside vegetation depends on maintenance by the landowners: Taking care of my streamside forests is of benefit to the environment, and that streamside forest provides a pleasing environment. This consideration also extends to native animals and their habitat as evidenced by such items as Shade in streamside forests benefits the creatures living in the creek, Streamside forest provides good habitat for creatures in the creek, and Streamside forests mean more habitat for native animals. The items in this factor also incorporate some understanding of appropriate streamside vegetation: Trees on the riverbanks are extremely good to have, Only grass on the streamsides to stabilise them is insufficient, Stabilising streamsides with bushes and trees works extremely well, Grass alone extremely inefficient holding the creek banks together; Growing bushes and trees works well in stabilising the stream banks, and an expression of aesthetic appreciation: Streamside forests are extremely pleasant.

While factor 1 did not exhibit statistical significance, it nevertheless reflects the findings from other research. Acknowledging human impact in land deterioration and thus the need for good land care practices, does not always lead to actual implementation of such. This is possibly due to the failure to recognise deterioration on one's own land (Burston \& Mathison, 1997; Cotching\& Sims, 2000; Curtis \& Robertson, 2003a; Dutcher et al., 2004; Kraack, 
2000; Vanclay, 1992). Therefore, landowners of streamside forest can very well acknowledge human impact and at the same time own forest in great need of improvement.

Of the two factors, factor 2 emerges as the highly significant predictor in the multiple regression analysis. Appreciation of environmental benefits and functions of streamside forest was here manifested by items that are representative of a biospheric view of the benefits of streamside forests: Native animals in the streamside forest are very enjoyable; Native animals in streamside forests are extremely good to have; The preservation of my streamside forests is valuable; Streamside forests are very good for the environment at large; Maintaining of streamside forests is not a waste of money and time; Streamside forests are very beneficial for the environment at large; The environment benefits if landowners care for their streamside forest. Native animals are at the top of the list, representing the joy of providing for and experiencing wildlife. The predominance of the belief in the general environmental benefits clearly outweighs the two items expressing belief in the biophysical functions of streamside forests: Streamside forests slow down flow of silt and sediments; Intact streamside forests will assure good water quality in my creek. The factor is firmly grounded in attitudes that represent beliefs that everything in nature has a function in the scheme of things. Finding the reforesting of the streamside forests desirable (item 6) expresses the general endorsement of the streamside forests. Herbohn (1999) also found this strong biospheric view in the context of forestry farming in North Queensland. The respondents ranked economic or commercial reasons much lower than personal satisfaction of knowing that tree planting is beneficial for the environment. Another Queensland study similarly found that the attitude component of "beliefs about the benefits rather than the cost of streamside zone management are critical for influencing the adoption of streamside zone management" (Fielding et al., 2005, p.19).

In regard to the streamside forest management practices component, it has to be mentioned that it could not be verified as such but was the sum of five self-reported physical descriptors of their streamside forest that were ticked by the landowner. This may define it as an unreliable measure. Conversely, it is perceivable that the indirect form of inquiry was actually an advantage in that it was not perceived as prying into their streamside forest condition and therefore elicited honest answers according to the respondents' perception.

\section{CONCLUSIONS}


This limited analysis of survey data on attitudes of landowners sheds some light on the main factors that are predictive of streamside land management practices within the context of this Far North Queensland study area. It showed that an appreciation of environmental and functional benefits of streamside forests together with an awareness of human impact on these zones explains $10 \%$ of the variance in good streamside management practices. This reflects similar environmental studies that found conservation oriented biospheric attitudes to be closely correlated to environmentally beneficial practices. Such attitudes are mainly represented by factor 2 in this study which was a significant contributor to the prediction in the first step of the multiple regression analysis.

This study highlights some important concepts that deserve consideration in the task of promoting good streamside forest management practices. It shows that one needs to reinforce the understanding of the human impact on the streamside zones and to support the beliefs in environmental benefits and biophysical functions of streamside forests in the tropics of North Queensland.

The research was undertaken as part of a PhD project of the first author in the Department of Psychology, James Cook University, Cairns QLD.

The authors gratefully acknowledge the generous help from the Cairns City Council and the Johnstone Shire Council who provided the addresses of landowners.

\section{REFERENCES}

Ajzen, I. (1991). The theory of planned behavior. Organizational Behavior and Human Decision Processes, 50, 179-211.

Armitage, C. J., \& Conner, M. (2001). Efficacy of the theory of planned behaviour: A metaanalytic review. Britisch Journal of Social Psychology, 40, 471-499.

Armour, J., Cogle, L., Rasiah, V., \& Russell, J. (2004). Sustaining the Wet Tropics: A regional plan for Natural Resource Management. (Vol. 2B Condition Report: Sustainable use.). Cairns, Australia: Rainforest CRC and FNQ NRM Ltd.

Bjornsson, K. T., Brodie, A., Dyer, B., Lukacs, G., Vella, K., Walker, D., et al. (2002). Riparian areas and on-farm wetlands in the Australian sugar industry. A review for the CRC for sustainable sugar production. A CRC Sugar Technical Publication, Townsville. 
Brodie, J. (2002). The effects of landuse on water quality in Australian north-east coastal catchment and coastal waterways. ACTFR Report No. 02/07: Australian Centre for Tropical Freshwater Research, James Cook University.

Brodie, J., Lewis, S., Mitchell, A., Bainbridge, Z., \& Waterhouse, J. (2009). Pollutant discharge management target setting for rivers in the Great Barrier Reef catchment area. Challenges in the Environmental Science and Engineering - Conference.

Brodie, J. E., \& Mitchell, A. W. (2005). Nutrients in Australian tropical rivers: changes with agricultural development and implications for receiving environments. Marine and Freshwater Research, $56(279$ - 302).

Burston, J., \& Mathison, M. (1997). 'There is nothing wrong with my watercourse!!': the art of engaging the community. Proceedings of the National Conference: Landcare Changing Australia, Adelaide SA, 215-216.

Cleary, D., \& Amprimo, J. (1995). Developing education resources on catchment management based on a knowledge of attitudes and perceptions. Paper presented at the Australian Water and Wastewater Association Federal Convention, 2-6 Apr 1995, Sydney NSW, Proceedings.

Cotching, B., \& Sims, C. (2000). Changes in farmer perceptions towards soil conservation and management in north-west Tasmania. Rural Society, 10(3), 379-392.

Curtis, A., \& Robertson, A. (2003a). Understanding landholder management of river frontages. The Goulburn Broken. Ecological Management \& Restoration, 4(4), 45-54.

Curtis, A., \& Robertson, A. (2003b). Who are program managers working with and does it matter? Natural Resource Management, 6(2), 25-32.

Curtis, A., Shindler, B., \& Wright, A. (2002). Sustaining local watershed initiatives: Lessons from landcare and watershed councils. Journal of the American Water Resources Association., 38(5), 1207-1216.

Devlin, M. J., \& Brodie, J. (2005). Terrestrial discharge into the Great Barrier Reef Lagoon:nutrient behavior in coastal waters. Marine Pollution Bulletin 51, 9-22. 
Dixon, R. M. W. (1991). Words of Our Country. St Lucia, QLD, Australia: University of Queensland Press.

Dutcher, D. D., Finley, J. C., Luloff, A. E., \& Johnson, J. (2004). Landowners perceptions of protecting and establishing riparian forests: A qualitative analysis. Society and Natural Resources, 17, 319-332.

Eagley, A. H., \& Chaiken, S. (1993). The Psychology of Attitudes. Fort Worth: Harcourt Brace Jovanovich.

Fenton, M. (2004). An investigation of capacity and capacity building requirements in relation to natural resource management in the wet tropics. Report prepared for FNQ NRM Ltd., Innisfail.

Fielding, K. S., Terry, D. J., Masser, B. M., Bordia, P., \& Hogg, M. A. (2005). Explaining landholders' decisions about riparian zone management: The role of behavioural, normative, and control beliefs. Journal of Environmental Management, 77, 12-21.

FNQ NRM Ltd \& Rainforest CRC (2004). Sustaining the Wet Tropics: A Regional Plan for Natural Resource Management 2004-2008. Draft for public comment. Innisfail QLD, Australia.

GBRMPA (2001). Great Barrier Reef Catchment Water Quality Action Plan. Report to the Ministerial Council on targets for pollutants loads: Great Barrier Reef Marine Park Authority,Townsville.

Gilbert, M. (2001). Population and major land use in the Great Barrier Reef Catchment area: Spatial and temporal trends. Great Barrier Reef Marine Park Authority, Townsville

Haynes, D. (2001). Great Barrier Reef Water Quality: Current Issues. Great Barrier Reef Marine Park Authority: GBRMPA Report 98.

Herbohn, J. (1999). Landholder attitudes to farm forestry in north Queensland. (http://rainforest-crc.jcu.edu.au/publications/inforsheets/farmForestry.). 
Herron, N. F., \& Hairsine, P. B. (1998). A scheme for evaluating the effectiveness of riparian zones in reducing overland flow to streams. Australian Journal of Soil Research, 36(4), 683699.

Hobbs, R. J., Hussey, B. M., \& Saunders, D. A. (1990). Nature conservation: the role of corridors. Conference Notice. Journal of Environmental Management, 31, 93-94.

Klapproth, J. C., \& Johnson, J. E. (1999a). Understanding the science behind riparian forest buffers: Effects on water quality. Virginia Cooperative Extension. Publication Number 420151. : Virginia Polytechnic Institute and State University.

Klapproth, J. C., \& Johnson, J. E. (1999b). Understanding the science behind riparian forest buffers: Factors influencing adoption. Virginia Cooperative Extension. Publication Number 420-151.: Virginia Polytechnic Institute and State University.

Kraack, A. (2000). Why do growers do what they do? Townsville: Cooperative Research Centre for Sustainable Sugar Production.

Lovett, S., \& Price, P. (Eds.). (2007). Principles of riparian lands management. Braddon, ACT Australia: Land \& Water Australia.

Mallawaarachchi, T., Ebert, S. P., Byron, P., \& Johnson, A. K. L. (1999). Community attitudes to environmental protection in cane growing regions. Townsville: CSIRO Tropical agriculture. http://irum.tag.csiro.au.

McKenzie-Mohr, D. (2000). Promoting sustainable Behavior: An introduction to communitybased social marketing. Journal of Social Issues, 56(1), 543-552.

McKerkow, L. A., Prosser, I. P., Grayson, R. B., \& Heiner, D. (2004). Performance of grass and rainforest buffers in the wet tropics, Far North Queensland. 2. Water quality. Australian Journal of Soil Research, 42(4), 485-498.

Productivity Commission (2003). Industries, land use and water quality in the Great Barrier Reef Catchment. Research Report, Canberra.

Queensland Government (2008). Reef Water Quality Protection Plan, from www.thepremier.qld.gov.au 
Rasiah, V., Armour, J. D., Menzies, N. W., Heiner, D. H., Donn, M. J., \& Mahendrarajah, S. (2003). Nitrate retention under sugarcane in wet tropical Queensland deep soil profiles. Australian Journal of Soil Research, 41, 1145-1161.

Steg, L., \& Vlek, C. (2008). Encouraging pro-environmental behaviour: An integrative review and research agenda. Journal of Environmental Psychology, in press, 1-9.

Thomson, D., \& Pepperdine, S. (2003). Assessing community capacity for riparian restoration. In P. Price \& S. Love (Eds.), Land \& Water Australia. Canberra: Land \& Water Australia.

Vanclay, F. (1992). Farmer attitudes or media depiction of land degradation: Which is the barrier to adoption? Regional Journal of Social Issues, 26, 41-50.

Vogel, S. (1996). Farmer's environmental attitudes and behavior. A case study for Austria. Environment and Behavior, 28(5), 591-613.

Webb, A. A., \& Erskine, W. D. (2003). A practical scientific approach to riparian vegetation rehabilitation in Australia. Journal of Environmental Management, 68(2), 329-341.

Werren, G. L., \& Arthington, A. (2002). The assessment of riparian vegetation as an indicator of stream condition, with particular emphasis on the rapid assessment of flow-related impacts. In A. J. Franks, J. Playford \& A. Shapcott (Eds.), Landscape Health of Queensland (pp. 194-222). Brisbane: The Royal Society of Queensland.

Werren, G. L., Hunt, R., \& Brodie, A. (2002). 'Arteries of the Landscape" - wetlands and the nature and function of riparian systems - implications for best practice management in canegrowing areas. In 'Managing Soils, Nutrients and the Environment for Sustainable Sugar Production'. Bruce, R.C. (ed.) Cooperative Research Centre for Sustainable Sugar Production, CSIRO/James Cook University, Townsville:33-46.

Wet Tropics Management Authority (2004). Wet Tropics Conservation Strategy - the conservation, rehabilitation and transmission to future generations of Wet Tropics World Heritage Area: Cairns: WTMA.

World Heritage List (2009). http://whc.unesco.org 
etropic 8 (2009): Flick, Caltabiano, \& Bentrupperbaumer, Far North Queensland 